\title{
Cyclopolymerization XXIII. Design of Unconjugated Dienes with High Polymerizability Using Functional Groups with No Homopolymerization Tendency and Synthesis of Completely Cyclized Polymers Therefrom: Radical Polymerizations of $N$-Substituted $N$-Allyl-2-(methoxycarbonyl)allylamines
}

\author{
Qing-Qing LiU, Toshiyuki KodaIRa, ${ }^{\dagger}$ Michio UrushisaKI, and Tamotsu Hashimoto \\ Department of Materials Science and Engineering, \\ Faculty of Engineering, Fukui University, \\ Fukui 910, Japan
}

(Received June 19, 1996)

\begin{abstract}
N$-Substituted $N$-allyl-2-(methoxycarbonyl)allylamines (SAMC) were synthesized and polymerized to establish a methodology for designing unconjugated dienes with not only a high cyclization tendency but also high polymerizability. The $N$-substituents investigated were methyl, propyl, tert-butyl, and phenyl groups. Detailed examination of the properties of the unconjugated dienes reported so far indicated the use of functional groups with a higher conjugative nature together with no homopolymerization tendency to be essential to achieve this purpose. SAMC were designed since $\alpha$-substituted acrylates have a considerably higher conjugative nature, even if they do not have homopolymerization tendencies. In fact, conjugation between $\mathrm{C}=\mathrm{C}$ and $\mathrm{C}=\mathrm{O}$ double bonds of the acryloyl groups of SAMC and $N$-substituted $N$-propyl-2-(methoxycarbonyl)allylamines (SPMC), one of the monofunctional counterparts of SAMC, were found to be considerably effective. No detectable homopolymer could be obtained from SPMC. It is well known that allyl compounds, the other monofunctional counterparts of SAMC, have extremely lower polymerization tendencies. SAMC were converted to completely cyclized polymers by use of a radical initiator with a high polymerization rate, especially in the case of methyl and propyl derivatives. Their polymerizabilities were correlated with the conjugative nature of $\mathrm{C}=\mathrm{C}$ and $\mathrm{C}=\mathrm{O}$ double bonds of their acryloyl groups, except for the phenyl derivative. ESR studies on the methyl derivative suggested that its polymerization initiates through the acryloyl group.

KEY WORDS Radical Cyclopolymerization / 1,6-Diene / $\alpha$-Substituted Acryloyl Group / Allyl Group / Propagating Radical / High Cyclopolymerizability /
\end{abstract}

The principle for monomer design for the synthesis of highly cyclized polymers from bifunctional monomers has been established. ${ }^{1-5}$ It states that the bifunctional monomers whose monofunctional counterparts do not polymerize are likely to give rise to highly cyclized polymers, if they polymerize at all. However, the problem has been the lower polymerization tendencies of the unconjugated dienes synthesized under this principle. For this reason, we searched for monomers which not only have a high cyclization tendency but also high polymerizability. Detailed examination of the properties of unconjugated dienes designed under the principle suggested that the main reason for low polymerizability stems from the unconjugative nature of the functional groups and steric hindrance of substituents which interfere with the addition of an attacking radical. The use of functional groups with a higher conjugative nature together with no homopolymerization tendencies would thus appear essential to achieve the purpose. ${ }^{6} \mathrm{~N}$-Substituted $\mathrm{N}$-allyl-2-(methoxycarbonyl)allylamines (SAMC) were designed as monomers which fulfill the conditions, since $\alpha$-substituted acrylates have considerably higher conjugative nature, even if they do not have homopolymerization tendencies. ${ }^{7}$ Their polymerization behavior was studied along with that of $N$-substituted $N$-propyl-2-(methoxycarbonyl)allylamines (SPMC), a class of monofunctional counterparts of SAMC. Cyclopolymerizations of several symmetrical and unsymmetrical unconjugated dienes having $\alpha$-substituted acryloyl groups have already been reported. ${ }^{8-16}$ However, their

$\dagger$ To whom correspondence should be addressed. cyclopolymerizabilities have not been investigated in terms of the polymerizabilities of monofunctional counterparts. Preliminary results reported on $N$-methyl- $N$-allyl2-(methoxycarbonyl)allylamine (MAMC) suggest the validity of the idea proposed. ${ }^{6}$ The goal of this work is to establish the concept with additional evidence provided. ESR studies on MAMC and $N$-methyl- $N$-propyl-2-(methoxycarbonyl)allylamine (MPMC) were also undertaken to obtain information on the mechanism of polymerization of these monomers.<smiles>C=CCN(P)CC(=C)C(=O)OC</smiles><smiles>C=C(CN(P)CCC)C(=O)OC</smiles>

\begin{tabular}{l|l|l} 
SAMC & \multicolumn{1}{|c|}{$\mathrm{R}$} & SPMC \\
\hline MAMC & $\mathrm{CH}_{3}$ & MPMA \\
PAMC & $\mathrm{CH}_{2} \mathrm{CH}_{2} \mathrm{CH}_{3}$ & PPMC \\
BAMC & ${\mathrm{C}\left(\mathrm{CH}_{3}\right)_{3}}^{\text {BPMC }}$ & \\
PhAMC & & \\
& & PhPMC
\end{tabular}

\section{EXPERIMENTAL}

\section{Materials}

SAMC and SPMC were synthesized by the equimolar 
Completely Cyclized Polymers from Unsymmetrical 1,6-Dienes

Table I. Boiling points and elementary analysis

\begin{tabular}{|c|c|c|c|c|c|c|c|}
\hline \multirow{2}{*}{ Monomer } & \multirow{2}{*}{$\frac{\mathrm{bp}^{\mathrm{a}}}{{ }^{\circ} \mathrm{CmmHg}{ }^{-1}}$} & \multicolumn{2}{|c|}{$\mathrm{C} / \%$} & \multicolumn{2}{|c|}{$\mathrm{H} / \%$} & \multicolumn{2}{|c|}{$\mathrm{N} / \%$} \\
\hline & & Calcd & Found & Calcd & Found & Calcd & Found \\
\hline $\mathrm{BAMC}^{\mathrm{c}}$ & $78 / 2$ & 68.21 & 67.95 & 10.02 & 9.94 & 6.63 & 6.57 \\
\hline PhAMC & $105 / 0.2$ & 72.39 & 72.23 & 7.81 & 7.51 & 6.03 & 5.95 \\
\hline $\mathrm{PPMC}^{\mathrm{e}}$ & $88 / 3$ & 66.30 & 66.03 & 10.62 & 10.54 & 7.03 & 7.05 \\
\hline BPMC $^{f}$ & $65 / 0.1$ & 67.57 & 67.52 & 10.87 & 10.86 & 6.57 & 6.61 \\
\hline $\mathrm{PhPMC}^{\mathrm{g}}$ & $123 / 0.2$ & 71.76 & 72.03 & 8.60 & 8.42 & 5.98 & 5.90 \\
\hline
\end{tabular}

${ }^{\mathrm{a}}$ Not corrected. ${ }^{\mathrm{b}} N$-Propyl- $N$-allyl-2-(methoxycarbonyl)allylamine. ${ }^{\mathrm{c}} N$-tert-Butyl- $N$-allyl-2-(methoxycarbonyl)allylamine. ${ }^{\mathrm{d}} N$-Phenyl- $N$-allyl-2(methoxycarbonyl)allylamine. ${ }^{\mathrm{e}} N, N$-Dipropyl-2-(methoxycarbonyl)allylamine. ${ }^{\mathrm{f}} N$-tert-Butyl- $N$-propyl-2-(methoxycarbonyl)allylamine. ${ }^{\mathrm{g}} N$-Phenyl$\mathrm{N}$-propyl-2-(methoxycarbonyl)allylamine.

reaction between methyl $\alpha$-(bromomethyl)acrylate (BMA) and corresponding amines based on the procedure for the preparation of MAMC and MPMC ${ }^{6}$ Crude products obtained were subjected to repeated distillations to give pure liquids. Yields of the final stage of the synthesis of these monomers were from 40 to $60 \%$ after distillations two times. The supposed structure was confirmed by NMR and results of elementary analyses. The boiling points (bp) and results of the elementary analyses are shown in Table I. Chemical shifts of the characteristic absorption peaks of ${ }^{1} \mathrm{H}$ and ${ }^{13} \mathrm{C}$ NMR spectra of SAMC and SPMC other than MAMC and MPMC are as follow. ${ }^{1} \mathrm{H}$ NMR for PAMC: $\delta=6.22(\mathrm{~s}, 1 \mathrm{H}), 5.82(\mathrm{~m}, 1 \mathrm{H}), 5.81$ $(\mathrm{s}, 1 \mathrm{H}), 5.12(\mathrm{t}, 2 \mathrm{H}), 3.75(\mathrm{~s}, 3 \mathrm{H}), 3.25(\mathrm{~s}, 2 \mathrm{H}), 3.07(\mathrm{~d}$, $2 \mathrm{H}), 2.39$ (t, 2H), 1.46 (sextet, $2 \mathrm{H})$, and $0.86 \mathrm{ppm}(\mathrm{t}, 3 \mathrm{H})$. ${ }^{13} \mathrm{C}$ NMR for PAMC: $\delta=167.6,138.7,136.1,125.9$, 116.9, 57.1, 55.8, 54.2, 51.7, 20.4, and $11.8 \mathrm{ppm} .{ }^{1} \mathrm{H}$ NMR for PPMC: $\delta=6.19(\mathrm{~s}, 1 \mathrm{H}), 5.81(\mathrm{~s}, 1 \mathrm{H}), 3.75(\mathrm{~s}, 3 \mathrm{H})$, $3.22(\mathrm{~s}, 2 \mathrm{H}), 2.36(\mathrm{t}, 4 \mathrm{H}), 1.44$ (sextet, $4 \mathrm{H})$, and $0.85 \mathrm{ppm}$ $(\mathrm{t}, 6 \mathrm{H}) .{ }^{13} \mathrm{C}$ NMR for PPMC: $\delta=167.8,139.1,125.6$, $56.2,55.0,51.6,20.4$, and $11.9 \mathrm{ppm} .{ }^{1} \mathrm{H}$ NMR for BAMC: $\delta=6.21(\mathrm{~s}, 1 \mathrm{H}), 6.03(\mathrm{~s}, 1 \mathrm{H}), 5.80(\mathrm{~m}, 1 \mathrm{H}), 4.86(\mathrm{~m}, 2 \mathrm{H})$, $3.74(\mathrm{~s}, 3 \mathrm{H}), 3.33$ (s, 2H), 3.19 (d, 2H), and $1.08 \mathrm{ppm}(\mathrm{s}$, 9H). ${ }^{13} \mathrm{C}$ NMR for BAMC: $\delta=167.7,141.1,138.7,125.7$, 115.2, 55.0, 53.3, 51.5, 49.2, and $27.3 \mathrm{ppm} .{ }^{1} \mathrm{H}$ NMR for BPMC: $\delta=6.22(\mathrm{~s}, 1 \mathrm{H}), 6.10(\mathrm{~s}, 1 \mathrm{H}), 3.75(\mathrm{~s}, 3 \mathrm{H}), 3.31$ (s, 2H), $2.45(\mathrm{t}, 2 \mathrm{H}), 1.29$ (sextet, 2H), 1.04 (s, 9H), and $0.80 \mathrm{ppm}(\mathrm{t}, 2 \mathrm{H}) .{ }^{13} \mathrm{C}$ NMR for BPMC: $\delta=167.8,142.0$, $125.5,54.8,53.4,41.5,51.1,27.1 .23 .6$, and $11.9 \mathrm{ppm}$. ${ }^{1} \mathrm{H}$ NMR for PhAMC: $\delta=7.18(\mathrm{~m}, 2 \mathrm{H}), 6.67(\mathrm{~m}, 3 \mathrm{H})$, $6.26(\mathrm{~s}, 1 \mathrm{H}), 5.86(\mathrm{~m}, 1 \mathrm{H}), 5.60(\mathrm{~s}, 1 \mathrm{H}), 5.19(\mathrm{~m}, 2 \mathrm{H})$, $4.16(\mathrm{~s}, 2 \mathrm{H}), 3.93(\mathrm{~d}, 2 \mathrm{H})$, and $3.79 \mathrm{ppm}(\mathrm{s}, 3 \mathrm{H}) .{ }^{13} \mathrm{C}$ NMR for PhAMC: $\delta=166.9,148.2,135.6,133.4,129.1$, $125.0,116.6,116.4,112.0,52.9,51.8$, and $51.2 \mathrm{ppm} .{ }^{1} \mathrm{H}$ NMR for PhPMC: $\delta=7.20(\mathrm{~m}, 2 \mathrm{H}), 6.63(\mathrm{~m}, 3 \mathrm{H}), 6.23$ $(\mathrm{s}, 1 \mathrm{H}), 5.53(\mathrm{~s}, 1 \mathrm{H}), 4.16(\mathrm{~s}, 2 \mathrm{H}), 3.79(\mathrm{~s}, 3 \mathrm{H}), 3.26(\mathrm{t}$, $2 \mathrm{H}), 1.65$ (sextet, 2H), and $0.93 \mathrm{ppm}(\mathrm{t}, 3 \mathrm{H}) .{ }^{13} \mathrm{C} \mathrm{NMR}$ for PhPMC: $\delta=167.0,147.8,135.4,129.2,125.0,116.0$, $111.7,52.9,51.8,51.6,20.5$, and $11.4 \mathrm{ppm}$.

BMA,${ }^{17} N$-methylallylamine, ${ }^{18}$ and $N$-methylpropylamine $^{18}$ were prepared by the reported procedure. $N$ Propyl-, $N$-tert-butyl- and $N$-phenylallylamines, and $N$ tert-butyl- and $N$-phenylpropylamines were synthesized according to the procedure reported for the synthesis of $N, N$-diethylallylamine. ${ }^{19}$

Commercial 2,2'-azobisisobutyronitrile (AIBN) was recrystallized from ethyl alcohol. All common solvents were purified by the usual methods.

\section{Polymerization}

Polymerizations were performed in sealed tubes. A given amount of monomer and initiator were placed in glass ampoules, which were then subjected to several freeze-pump-thaw cycles and sealed. After polymerization in a constant-temperature bath, the polymerization mixtures were poured into excess petroleum ether. The polymers were reprecipitated from benzene solution into petroleum ether to obtain pure polymers for measurements. Conversions of the monomer for PAMC were calculated from the weight of the polymer. In the case of BAMC and PhAMC, they were determined from the residual monomer concentration measured by gas chromatography with tetralin as the internal standard, since some portion of their polymers was found to be soluble in petroleum ether. Monomer conversions determined by the precipitation method for PAMC were essentially the same as those by gas chromatography. The absence of polymer in the polymerization systems of PPMC, BPMC, and PhPMC was confirmed by the precipitation method using petroleum ether as the non-solvent along with ${ }^{1} \mathrm{H}$ NMR using tetralin as an internal standard.

\section{Measurements}

The molecular weight distribution of poly(PhAMC) was determined by size-exclusion chromatography (SEC) in tetrahydrofuran on a Shimadzu chromatograph equipped with three polystyrene gel columns (Shodex $80 \mathrm{M} \times$ 2 and KF-203.5) and ultraviolet/refractive index dualdetectors. The number-average molecular weight $\left(M_{n}\right)$ and ratio of weight- to number-average molecular weight $\left(M_{w} / M_{n}\right)$ were calculated on the basis of polystyrene calibration. ${ }^{1} \mathrm{H}$ NMR and ${ }^{13} \mathrm{C}$ NMR spectra were taken on a JEOL JNM-GX-270 FT NMR spectrometer using $\mathrm{CDCl}_{3}$ and tetramethylsilane as solvent and internal standard, respectively. The ESR spectra were recorded using a flow system with a TE011 mode cylindrical cavity of a JEOL JES-FE1X spectrometer. The flow rate used was $2.5 \mathrm{~cm}^{3} \mathrm{~s}^{-1}$. This flow rate corresponds to the time lag before measurement of about $0.03 \mathrm{~s}$. The method used for the generation of amino radicals was similar to that previously described. ${ }^{20}$ The $\mathrm{pH}$ was adjusted to 1.4 by adding sulfuric acid. The monomer concentration used was usually $0.05 \mathrm{~mol} \mathrm{dm}^{-3}$. All measurements were made at room temperature $\left(25 \pm 2^{\circ} \mathrm{C}\right)$. Viscosity was measured using a Ubbelohde viscometer at $30^{\circ} \mathrm{C}$ in $N, N$ dimethylformamide. 
Q.-Q. LiU et al.

Table II. Polymerizations of SAMC and related compounds at $60^{\circ} \mathrm{C}$

\begin{tabular}{|c|c|c|c|c|c|c|c|}
\hline \multirow{2}{*}{ No. } & \multirow{2}{*}{ Monomer } & \multirow{2}{*}{$\frac{[\mathrm{M}]_{0}}{\mathrm{M}}$} & \multirow{2}{*}{$\frac{[\mathrm{AIBN}]_{0}}{\mathrm{M} \times 10^{3}}$} & \multirow{2}{*}{$\frac{\text { Time }}{\mathrm{h}}$} & \multirow{2}{*}{$\frac{\mathrm{DC}^{\mathrm{a}}}{\%}$} & \multirow{2}{*}{$\frac{[\eta]}{\mathrm{dLg}^{-1}}$} & \multirow{2}{*}{$\begin{array}{c}\text { Conv. } \\
\%\end{array}$} \\
\hline & & & & & & & \\
\hline $1^{\mathrm{b}}$ & MAMC & bulk & 6.06 & 0.3 & 100 & 0.24 & 7 \\
\hline $2^{\mathrm{b}}$ & MAMC & bulk & 6.06 & 0.7 & 100 & 0.28 & 20 \\
\hline $3^{b}$ & MAMC & 2.32 & 6.06 & 1 & 100 & & 21 \\
\hline 4 & PAMC & bulk & 28.0 & 0.5 & 100 & 0.14 & 15 \\
\hline 5 & PAMC & bulk & 28.0 & 0.8 & 100 & & 36 \\
\hline 6 & PAMC & bulk & 28.0 & 1 & 100 & & 77 \\
\hline 7 & BAMC & bulk & 28.0 & 2 & 100 & & 45 \\
\hline 8 & BAMC & bulk & 28.0 & 4 & 100 & 0.16 & 78 \\
\hline $9^{c}$ & PhAMC & bulk & 28.0 & 2 & 100 & & 5 \\
\hline 10 & PhAMC & bulk & 28.0 & 10 & 100 & & 36 \\
\hline $11^{\mathrm{b}}$ & MPMC & bulk & 112 & 48 & & & 0 \\
\hline 12 & PPMC & bulk & 112 & 48 & & & 0 \\
\hline 13 & BPMC & bulk & 112 & 48 & & & 0 \\
\hline 14 & PhPMC & bulk & 112 & 48 & & & 0 \\
\hline $15^{\mathrm{d}}$ & MAMA & bulk & 143 & 15 & 93 & & 35 \\
\hline $16^{\mathrm{e}}$ & BAMA & bulk & 110 & 12 & 100 & & 41 \\
\hline $17^{\mathrm{e}}$ & PhAMA & bulk & 99 & 12 & 94 & & 33 \\
\hline $18^{\mathrm{f}}$ & MAA & 2.31 & 6.06 & 1 & 60 & & 23 \\
\hline
\end{tabular}

${ }^{\mathrm{a}}$ Degree of cyclization. ${ }^{\mathrm{b}}$ Quoted from ref $6 .{ }^{\mathrm{c}} M_{n}=2 \times 10^{4}, M_{w} / M_{n}=2.0$ determined by SEC. ${ }^{\mathrm{d}}$ Quoted from ref $2 .{ }^{\mathrm{e}}$ Quoted from ref $22 .{ }^{\mathrm{f}}$ Quoted from ref 21 .

\section{RESULTS}

\section{Polymerization of SAMC and SPMC}

The results of the polymerization of SAMC and SP$\mathrm{MC}$ are summarized in Table II. Reported results of $N$ methylacrylamide (MAA) ${ }^{21}$ and $N$-substituted methacrylamides (RAMA) such as $N$-methyl-, ${ }^{2} N$-tert-butyl-, ${ }^{22}$ and $N$-phenylmethacrylamides ${ }^{22}$ (MAMA, BAMA, and PhAMA, respectively) are also given in Table II for comparison. SAMC yielded high polymers, while no detectable polymer could be obtained from SPMC, even after prolonged polymerization time. This leads to the conclusion that the monoene counterparts of SAMC have essentially no homopolymerization tendency, because it may be reasonably assumed that the other monofunctional counterparts of SAMC, allyl derivatives, have extremely low polymerizability based on ${ }^{13} \mathrm{C}$ NMR studies of the allyl group of SAMC shown later. The poly(SAMC) samples are soluble in common solvents, which suggests the formation of highly cyclized polymers. In fact, no pendant double bonds could be detected in ${ }^{1} \mathrm{H}$ NMR spectra of poly(SAMC) (see next section). That the polymerizations were carried out in bulk is indication of how high the cyclization tendency of SAMC is. These results could be additional support for the principle for the monomer design for the synthesis of highly cyclized polymers mentioned above. Molecular weights and their distribution of poly(SAMC) obtained could not be determined by SEC except for poly(PhA$\mathrm{MC}$ ), since they were not detected under the conditions described in the experimental section. For this reason, viscosities were measured to obtain information on molecular size.

It can be seen from Table II that polymerization tendencies of SAMC are much higher than those of RAMA $^{2,22}$ and almost comparable to that of MAA ${ }^{21}$ except for PhAMC. The monofunctional counterparts of RAMA do not polymerize, while one monoenconterpart of MAA, $N$-methyl- $N$-propylacrylamide, can be

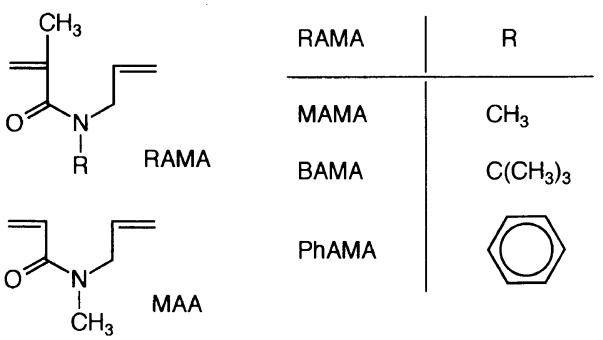

Scheme 2.

polymerized to high polymers. Accordingly, RAMA are polymerized to yield highly cyclized polymers but with a lower polymerization rate, ${ }^{2,22}$ while MAA has high polymerizability but its cyclization tendency is low. ${ }^{21}$ Higher polymerizabilities in addition to higher cyclization tendencies could be achieved in SAMC especially in the case of methyl and propyl derivatives, irrespective of the fact that both of their monofunctional counterparts have extremely low polymerization tendencies as in RAMA. Another characteristic feature of polymerization behavior of SAMC is that $N$-substituents influence significantly the polymerization of SAMC different from that of RAMA as can be seen from Table II. ${ }^{2,22}$

\section{Structure of Poly $(S A M C)$}

The repeating units which are expected to appear in poly(SAMC) are 1-4 shown in Scheme 3. ${ }^{1} \mathrm{H}$ NMR spectra of poly(SAMC) are illustrated in Figure 1 along with absorptions due to olefin protons of SAMC. These
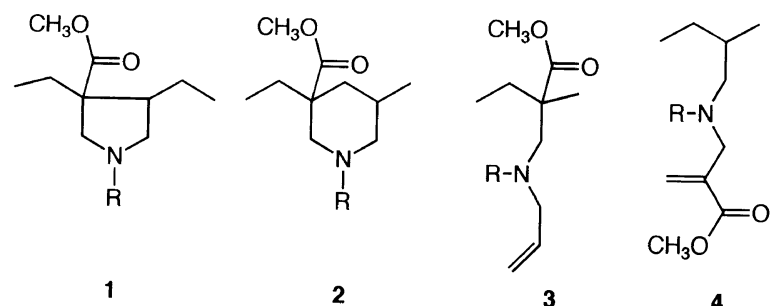

Scheme 3. 

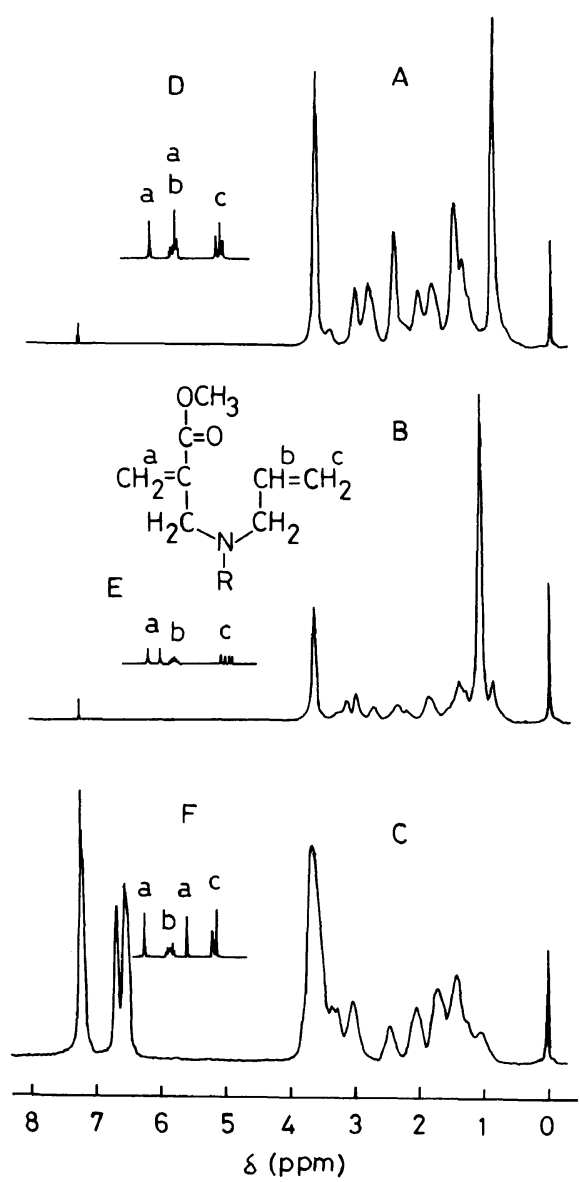

Figure 1. ${ }^{1} \mathrm{H}$ NMR spectra of poly(SAMC) and SAMC: A, poly(PAMC) (No. 5 in Table I) measured at $50^{\circ} \mathrm{C}$; B, poly(BAMC) (No. 7 in Table II); C, poly(PhAMC) (No. 10 in Table II); D, E, and F are olefin protons of PAMC, BAMC, and PhAMC, respectively.

polymers do not contain practically any pendant unsaturations. This means that repeating units of poly(SAMC) consist of structures $\mathbf{1}$ and/or $\mathbf{2}$. For the present, we do not have sufficient data to determine the repeating unit, 5- and/or 6-membered rings, and further study is necessary.

\section{NMR Studies of SAMC and Related Compounds}

Chemical shifts of $\mathrm{C}=\mathrm{C}$ double bonds $\left(\mathrm{C}_{\beta} \mathrm{H}_{2}=\mathrm{C}_{\alpha}<\right)$ and carbonyl carbons of the acryloyl groups of SAMC and related compounds obtained by measuring ${ }^{13} \mathrm{C}$ NMR spectra are summarized in Table III. $\delta_{\mathrm{C}_{\alpha}}$ and $\delta_{\mathrm{C}_{\beta}}$ values shift to a higher and lower magnetic field, respectively, with a linear relationship when $e$ values of the monomers become larger with increasing electronattracting power of substituents. ${ }^{23}$ This is because effective conjugation between $\mathrm{C}=\mathrm{C}$ and $\mathrm{C}=\mathrm{O}$ double bonds reduces the electron density on $\mathrm{C}=\mathrm{C}$ double bonds. This means that $\Delta \delta$ obtained by subtracting $\delta_{\mathrm{C}_{\beta}}$ from $\delta_{\mathrm{C}_{\alpha}}$ reflect the influence of substituents more effectively than their respective values. The stronger the electron-attracting power of the substituents, the smaller the value. Comparison of the $\Delta \delta$ of SAMC indicates that conjugation between olefin and carbonyl double bonds in these compounds changes depending on the substituents on nitrogen. Their variation suggests that $\Delta \delta$ increase with bulkiness of substituents except for the phenyl group. This means that bulkiness of the sub-
Table III. ${ }^{13} \mathrm{C}$ Chemical shifts of $\mathrm{C}_{\beta} \mathrm{H}_{2}=\mathrm{C}_{\alpha}<$ and carbonyl carbons of acryloyl groups of SAMC and related compounds in $\mathrm{CDCl}_{3}$

\begin{tabular}{|c|c|c|c|c|}
\hline \multirow{2}{*}{ Compound } & $\delta_{\mathrm{C}_{\beta}}$ & $\delta_{\mathrm{C}_{\alpha}}$ & $\delta_{\mathrm{C}=\mathrm{O}}$ & $\Delta \delta^{\mathrm{a}}$ \\
\hline & ppm & ppm & ppm & ppm \\
\hline MAMC $^{\mathrm{b}}$ & 126.8 & 137.8 & 162.4 & 11.0 \\
\hline $\mathrm{MPMC}^{\mathrm{b}}$ & 126.5 & 138.1 & 167.5 & 11.6 \\
\hline PAMC & 125.9 & 138.7 & 167.6 & 12.8 \\
\hline PPMC & 125.6 & 139.1 & 167.8 & 13.5 \\
\hline BAMC & 125.7 & 141.1 & 167.7 & 15.4 \\
\hline BPMC & 125.5 & 142.0 & 167.8 & 16.5 \\
\hline PhAMC & 125.0 & 135.6 & 166.9 & 10.6 \\
\hline PhPMC & 125.0 & 135.4 & 166.9 & 10.4 \\
\hline MMA & 125.5 & 136.3 & 168.0 & 10.8 \\
\hline $\mathrm{MDE}^{\mathrm{c}}$ & 126.0 & 136.9 & & 10.9 \\
\hline$n-\mathrm{BDE}^{\mathrm{c}}$ & 125.5 & 137.2 & & 11.7 \\
\hline$t-\mathrm{BDE}^{\mathrm{c}}$ & 124.4 & 138.6 & & 14.2 \\
\hline MAMA $^{\mathrm{d}}$ & 117.3 & 140.8 & 172.9 & 23.5 \\
\hline BAMA & 115.9 & 143.2 & 174.3 & 27.3 \\
\hline PhAMA & 119.4 & 143.2 & 171.5 & 23.8 \\
\hline MA & $115.1^{\mathrm{e}}$ & $141.4^{\mathrm{e}}$ & & 26.3 \\
\hline MI & & & $177.6^{\mathrm{f}}$ & \\
\hline
\end{tabular}

${ }^{\mathrm{a}} \delta_{\mathrm{C}_{\alpha}}-\delta_{\mathrm{C}_{\beta}}$. ${ }^{\mathrm{b}}$ Quoted from ref 6. ${ }^{\mathrm{c}}$ Quoted from ref 8 . MDE, $n$-BDE, and $t$-BDE are methyl, $n$-butyl, and tert-butyl esters of ether dimer of $\alpha$-hydroxymethyl acrylic acid, respectively. ${ }^{\mathrm{d}}$ Quoted from ref 22 . ${ }^{\mathrm{e}}$ Chemical shifts of olefin carbons of methallyl chloride (MA). Quoted from ref $6 .{ }^{\mathrm{f}}$ Chemical shifts of carbonyl carbon of methyl isobutyrate (MI). Quoted from ref 6.

stituents on nitrogen decreases the extent of conjugation between $\mathrm{C}=\mathrm{C}$ and $\mathrm{C}=\mathrm{O}$ double bonds. Coplanarity of these double bonds is considered to be distorted probably due to steric strain caused by bulky substituents. However, the conjugation of the acryloyl groups of SAMC and SPMC is considerably effective even in tert-butyl derivatives, judging from $\Delta \delta$ of these compounds and methallyl chloride (MA), the one of typical unconjugative monomers. Similar dependence of $\Delta \delta$ on substituents was also observed in a series of ether dimers of $\alpha$-(hydroxymethyl)acrylic acid esters, though substituents investigated in this case were those of ester groups. ${ }^{8,9}$ Chemical shifts of the carbonyl carbons also provide information on the conjugation between $\mathrm{C}=\mathrm{C}$ and $\mathrm{C}=\mathrm{O}$ double bonds, since the effective conjugation moves electrons in the olefin double bond into the carbonyl group and shifts the chemical shifts of the carbonyl carbons to higher magnetic fields. This can be understood from the largest chemical shift of the carbonyl carbon of methyl isobutyrate (MI) among the compounds listed in Table III. The chemical shifts of the methacryloyl carbons of RAMA are listed in Table III. These values indicate that the conjugative nature of their methacryloyl groups is extremely low even in MAMA and it is almost comparable to that of MA.

Radical polymerizabilities of allyl monomers were correlated to $\Delta \delta$ to show that those with a value of more than $6 \mathrm{ppm}$ for $\Delta \delta$ are reluctant to polymerize. ${ }^{24}$ This clearly indicates that the polymerization tendency of the allylic monofunctional counterparts of SAMC may be extremely low because of the large $\Delta \delta$ values (Table IV) observed for the allyl groups of SAMC.

\section{ESR Studies of MAMC and MPMC}

The elemental reactions related to radical cyclopo- 
Table IV. ${ }^{13} \mathrm{C}$ Chemical shifts of allyl $\left(\mathrm{C}_{\beta} \mathrm{H}_{2}=\mathrm{C}_{\alpha} \mathrm{H}-\right)$ carbons of SAMC in $\mathrm{CDCl}_{3}$

\begin{tabular}{|c|c|c|c|}
\hline \multirow{2}{*}{ SAMC } & $\delta_{\mathrm{C}_{\beta}}$ & $\delta_{\mathrm{C}_{\alpha}}$ & $\Delta \delta^{\mathbf{a}}$ \\
\hline & ppm & ppm & ppm \\
\hline MAMC & 117.4 & 135.7 & 18.3 \\
\hline PAMC & 116.9 & 136.1 & 19.2 \\
\hline BAMC & 115.2 & 138.7 & 23.5 \\
\hline PhAMC & 116.4 & 133.4 & 17.0 \\
\hline
\end{tabular}

${ }^{\mathrm{a}} \delta_{\mathrm{C}_{\alpha}}-\delta_{\mathrm{C}_{\beta}}$

lymerization of symmetrical unconjugated dienes are illustrated schematically in reactions (1)-(5). The prop-

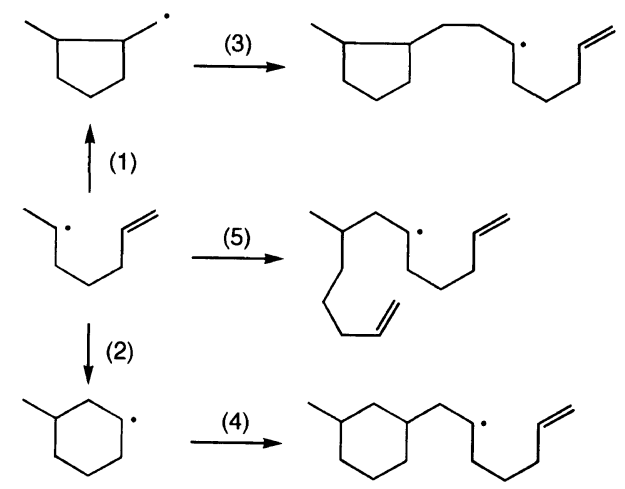

Scheme 4.

agating radicals that may appear during the polymerizations are two cyclized radicals and an uncyclized radical. Either radical or a mixture of them would be detected on ESR measurements depending on the ratedetermining step of cyclopolymerization and the cyclic structure formed. In the case of the unsymmetrical unconjugated dienes, the situation is rather complicated, because the number of radicals detected would be twice as high. However, if the interpretation of the results obtained is valid, the information on the reactivity of the two double bonds involved could be available in addition to that of the rate-determining step.

Figure 2(A) shows the ESR spectrum of MAMC obtained using $\cdot \mathrm{NH}_{2}$ as an initiating radical. Low signal to noise ratio of this spectrum does not allow unambiguous identification. Therefore, ESR of MPMC was measured under the same conditions. A spectrum obtained is illustrated in Figure 2(B). This is also complicated but comparison of these spectra suggests that they are due to essentially the same radical species. The extremely low homopolymerization tendency of MPMC indicates that radical $\mathbf{5}$ is the only possible radical which forms from this compound. This consideration permits us to attribute the spectrum shown in Figure 2(A) to radical 6. It has been assumed that the acryloyl group<smiles>CCCN(C)CC(CN)C(=O)OC</smiles>

5<smiles>C=CCN(C)CC(CN)C(=O)OC</smiles>

6
Scheme 5.
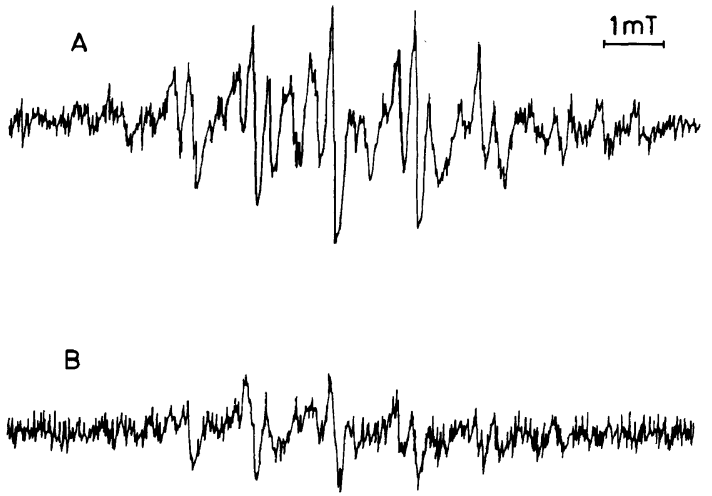

Figure 2. ESR spectra of MAMC (A) and MPMC (B).

is the double bond of higher reactivity between the two double bonds of MAMC. ${ }^{6}$ This is because the conjugative nature of the acryloyl group is much higher than that of its allyl group as can be seen from the chemical shifts of their $\mathrm{C}=\mathrm{C}$ double bonds summarized in Tables III and IV. These ESR studies confirm this assumption. Observation of only the uncyclized radical suggests that the rate-determining step for the cyclopolymerization of MAMC is intramolecular cyclization. Completely cyclized polymers can be obtained, even if intramolecular cyclization (6 and/or 7) is slower than intermolecular propagation ( 8 and/or 9 ), because intermolecular propagation (10) between the uncyclized radical and monomer never occurs in this polymerization system.

\section{DISCUSSION}

The effects of $N$-substituents on polymerization and conjugation between $\mathrm{C}=\mathrm{C}$ and $\mathrm{C}=\mathrm{O}$ double bonds of $\alpha$-substituted acryloyl groups of SAMC and SPMC can be clearly seen from the data summarized in Tables II and III. The results obtained suggest that non-homopolymerizability of SPMC is mainly due to steric factors, since their acryloyl groups have considerably higher conjugative nature. The definitely lower polymerizability of SPMC indicates that the probability of the formation of sequence 8 during the polymerization of SAMC is quite low and a chain end 7 may react with its own double bond to yield cyclized unit 9 and/or 10. Higher cyclopolymerization tendencies of SAMC indicate that the steric factors fatal to intermolecular propagation (10) leading to the sequence $\mathbf{8}$ are not unfavorable to intramolecular cyclization (6 and/or 7). Information on the rate constants for the elementary reactions on the polymerization of SAMC is essential to gain insight on polymerization. However, some characteristic features of their polymerizations can be pointed out, based on these results. Bulky substituents seem to prevent effective conjugation and retard polymerization. SAMC are considered to be incorporated into the polymeric chain mainly through their acryloyl groups, since their conjugative nature is higher than for allyl groups. In accordance with these considerations, ESR studies on MAMC revealed that the first step in the polymerization of MAMC predominantly involves the acryloyl group. For this reason, the polymerization rate would decrease, as the conjugative nature of the acryloyl groups decreases. Bulky substituents which decrease the extent 


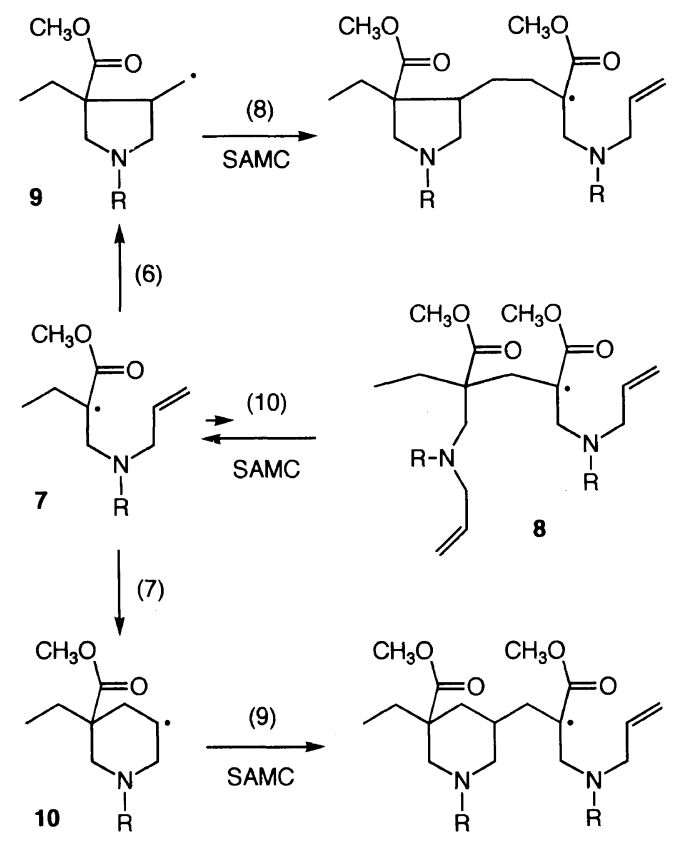

Scheme 6.

of conjugation might also be unfavorable sterically for the addition of the attacking radical to the $\alpha$-substituted acryloyl group. These substituent effects are rather different from those observed in the cyclopolymerization of ether dimers of $\alpha$-hydroxymethyl acrylates in which bulky substituents prevent the effective conjugation of their acryloyl groups but accelerate their polymerization. ${ }^{9}$ This is explained by a reduction in the termination reaction caused by steric hindrance of the bulky substituent, because such an acceleration of polymerization by bulky substituents has been observed in other monomers such as tert-butyl fumarate ${ }^{25}$ and adamantyl methacrylate $^{26}$ and is attributed to the reduction of the termination rate. Bulky $N$-substituents of SAMC might retard termination but the retardation of reaction between the attacking radical and acryloyl group of SAMC is considered to be larger than the former. This might be the reason for the variation of polymerizability of SAMC depending on substituents.

In the case of RAMA, the conjugation between $\mathrm{C}=\mathrm{C}$ and $\mathrm{C}=\mathrm{O}$ double bonds of their methacryloyl groups is substantially deteriolated even in MAMA whose substituent is methyl (compare the $\Delta \delta$ of RAMA and MA in Table III). This might be the reason why the polymerization tendencies of RAMA do not change even when the substituent is changed to a bulky one such as tertbutyl group.

The results obtained indicate that the use of functional groups with higher conjugative nature, along with extremely low polymerizability, is essential for the synthesis of monomers with, not only a high cyclization tendency, but also high polymerizability.

The arguments made above are concerned only with SAMC with substituents other than the phenyl group. The reason for slow polymerization of PhAMC is not clear at present. The conjugative nature of the acryloyl groups of PhAMC and PhPMC might not be argued based on the same ground as that of SAMC and SPMA without the phenyl group, since strong influence of the benzene ring on the chemical shifts through diamagnetic anisotropy is well known. Other factors such as chain transfer reactions to monomers might play important roles to suppress the overall polymerization rate in $\mathrm{PhAMC}$. Further study is necessary to determine the effect of the phenyl group on the polymerization behavior of SAMC.

Acknowledgment. This work was supported partly by a Grant-in-Aid for Scientific Research (No. 07651079) from the Ministry of Education, Science, and Culture of Japan, for which we are grateful.

\section{REFERENCES}

1. T. Kodaira and F. Aoyama, J. Polym. Sci., Polym. Chem. Ed., 12, 897 (1974).

2. T. Kodaira, M. Ishikawa, and O. Murata, J. Polym. Sci., Polym. Chem. Ed., 14, 1107 (1976).

3. T. Kodaira, M. Sakai, and K. Yamazaki, J. Polym. Sci., Polym. Lett. Ed., 13, 521 (1975).

4. T. Kodaira, K. Yamazaki, and T. Kitoh, Polym. J., 11, 377 (1979).

5. T. Kodaira and S. Sakaki, Makromol. Chem., 189, 1833 (1988).

6. T. Kodaira, T. Fujisawa, Q. Q. Liu, and M. Urushisaki, Macromolecules, 29, 484 (1996).

7. B. Yamada and S. Kobatake, Prog. Polym. Sci., 19, 1089 (1994).

8. J. W. Stansbury, Macromolecules, 24, 2029 (1991).

9. T. Tsuda and L. J. Mathias, Polymer, 35, 3317 (1994).

10. C. S. Marvel and R. D. Vest, J. Am. Chem. Soc., 79, 5771 (1957).

11. C. S. Marvel and R. D. Vest, J. Am. Chem. Soc., 81, 984 (1959).

12. G. N. Milford, J. Polym. Sci., 41, 295 (1959).

13. L. J. Mathias, R. F. Colletti, and A. Bielecki, J. Am. Chem. Soc., 113, 1550 (1991)

14. R. D. Thompson, W. L. Jarrett, and L. J. Mathias, Macromolecules, 25, 6455 (1992)

15. T. Tsuda and L. J. Mathias, Macromolecules, 26, 4734 (1993).

16. T. Tsuda and L. J. Mathias, Macromolecules, 26, 6359 (1993).

17. J. Villieras and M Rambaud, Synthesis, 924 (1982).

18. A. Morrison and H. Rinderknecht, J. Chem. Soc., 1478 (1950).

19. A. C. Cope and P. H. Towle, J. Am. Chem. Soc., 71, 3423 (1949).

20. C. Corvay, H. Fisher, and G. Giacometti, Z. Phys. Chem., 45, 1 (1965).

21. T. Kodaira and Y. Sumiya, Makromol. Chem., 187, 933 (1986).

22. T. Kodaira, M. Okumura, M. Urushisaki, and K. Isa, J. Polym. Sci., Part A, Polym. Chem., 31, 169 (1993).

23. K. Hatada, K. Nagata, and H. Yuki, Bull. Chem. Soc. Jpn., 43, 3267 (1970).

24. R. A. Vaidya and L. J. Mathias, J. Polym. Sci., Polym. Symp., 74, 243 (1986).

25. T. Otsu, T. Yasuhara, and A. Matsumoto, J. Macromol. Sci.-Chem., A25, 537 (1988).

26. A. Matsumoto, S. Tanaka, and T. Otsu, Macromolecules, 24, 4017 (1991) 